\title{
Best proximity point theorems for cyclic generalized proximal contractions
}

\author{
Ali Abkar1*, Narges Moezzifar' ${ }^{1}$, Azizollah Azizi ${ }^{1}$ and Naseer Shahzad²
}

\author{
"Correspondence: \\ abkar@sci.ikiu.ac.ir \\ ${ }^{1}$ Department of Mathematics, Imam \\ Khomeini International University, \\ P.O. Box 288, Qazvin, 34149, Iran \\ Full list of author information is \\ available at the end of the article
}

\begin{abstract}
In this paper we introduce the notion of a cyclic generalized proximal contraction, and then prove some best proximity point theorems in metric spaces. We will provide examples to illustrate our results.

MSC: 41A65; 46B20; 47H10

Keywords: best proximity point; approximatively compact set; cyclic generalized proximal contraction; cyclically complete pair; proximally complete pair; semi-sharp proximinal pair
\end{abstract}

\section{Introduction}

Fixed point theory is one of the most useful techniques in the study of nonlinear functional analysis. The Banach contraction principle is the simplest one corresponding to fixed point theory. This principle states that every contraction $T: X \rightarrow X$ on a complete metric space $(X, d)$ has a unique fixed point, that is, there exists $x \in X$ such that $T x=x$. This principle has been generalized by many researchers in several directions (see, for instance, [1-9]). On the other hand, the study of existence of fixed points for non-self mappings is a very interesting. More precisely, for two given nonempty closed subsets $A$ and $B$ of a complete metric space $(X, d)$, a non-self contraction $T: A \rightarrow B$ does not necessarily have a fixed point. In this case, it is quite natural to investigate an element $x \in X$ such that $d(x, T x)$ is minimum. A point $x \in A$ for which $d(x, T x)=d(A, B)$ is called a best proximity point of $T$, where

$$
d(A, B)=\inf \{d(x, y): x \in A, y \in B\} .
$$

Assume now that $T$ is a cyclic mapping, that $T$ is a self-mapping on $A \cup B$ with the property that $T(A) \subseteq B$ and $T(B) \subseteq A$. Again, a point $x \in A \cup B$ is a best proximity point of $T$ if $d(x, T x)=d(A, B)$; or equivalently, if $x$ is a solution of the minimization problem

$$
\min _{x \in A \cup B} d(x, T x) .
$$

In this paper, we denote the set of best proximity points of $T$ by $B_{\text {est }}(T)$.

Since a best proximity point reduces to a fixed point if $T$ is a self-mapping, the best proximity point theorems are natural generalizations of the Banach contraction principle.

(c) 2016 Abkar et al. This article is distributed under the terms of the Creative Commons Attribution 4.0 International License (http://creativecommons.org/licenses/by/4.0/), which permits unrestricted use, distribution, and reproduction in any medium, provided you give appropriate credit to the original author(s) and the source, provide a link to the Creative Commons license, and indicate if changes were made. 
We mention in passing that best proximity point theory is closely related to the following classical result in best approximation theory, due to Kay Fan [10], and its developments in other directions; see for instance Prolla [11], Sehgal and Singh [12,13] and the references therein.

Theorem 1.1 [10] If $A$ is a nonempty compact convex subset of a Hausdorff locally convex topological vector space $B$ and $T: A \rightarrow B$ is a continuous mapping, then there exists an element $x \in A$ such that $d(x, T x)=d(T x, A)$.

In 2012, Sadiq Basha and Shahzad [14] introduced the concept of a generalized proximal contraction mapping. Using this notion, they established best proximity point theorems under some mild conditions; indeed, their hypotheses were a combination of compactness and completeness conditions.

Definition 1.2 [14] Let $(X, d)$ be a metric space and let $A$ and $B$ be nonempty subsets of $X$. A mapping $T: A \rightarrow B$ is said to be a generalized proximal contraction of the first kind if there exist nonnegative real numbers $a, b, c, d$ with $a+b+c+2 d<1$, such that for all $x_{1}, x_{2}, u_{1}, u_{2} \in A$, the conditions $d\left(u_{1}, T x_{1}\right)=d\left(u_{2}, T x_{2}\right)=d(A, B)$ imply that

$$
d\left(u_{1}, u_{2}\right) \leq a d\left(x_{1}, x_{2}\right)+b d\left(x_{1}, u_{1}\right)+c d\left(x_{2}, u_{2}\right)+d\left[d\left(x_{1}, u_{2}\right)+d\left(x_{2}, u_{1}\right)\right]
$$

If $b=c$, then $a+2 c+2 d<1$ or $\frac{a+c+d}{1-c-d}<1$. So

$$
d\left(u_{1}, u_{2}\right) \leq a d\left(x_{1}, x_{2}\right)+c\left[d\left(x_{1}, u_{1}\right)+d\left(x_{2}, u_{2}\right)\right]+d\left[d\left(x_{1}, u_{2}\right)+d\left(x_{2}, u_{1}\right)\right] .
$$

Definition 1.3 [14] Let $(X, d)$ be a metric space and let $A$ and $B$ be nonempty subsets of $X$. A mapping $T: A \rightarrow B$ is said to be a generalized proximal contraction of the second kind if there exist nonnegative real numbers $a, b, c, d$ with $a+b+c+2 d<1$, such that for all $x_{1}, x_{2}, u_{1}, u_{2} \in A$, the conditions $d\left(u_{1}, T x_{1}\right)=d\left(u_{2}, T x_{2}\right)=d(A, B)$ imply that

$$
\begin{aligned}
d\left(T u_{1}, T u_{2}\right) \leq & a d\left(T x_{1}, T x_{2}\right)+b d\left(T x_{1}, T u_{1}\right)+c d\left(T x_{2}, T u_{2}\right) \\
& +d\left[d\left(T x_{1}, T u_{2}\right)+d\left(T x_{2}, T u_{1}\right)\right] .
\end{aligned}
$$

If $b=c$, then $a+2 c+2 d<1$ or $\frac{a+c+d}{1-c-d}<1$. So

$$
\begin{aligned}
d\left(T u_{1}, T u_{2}\right) \leq & a d\left(T x_{1}, T x_{2}\right)+c\left[d\left(T x_{1}, T u_{1}\right)+d\left(T x_{2}, T u_{2}\right)\right] \\
& +d\left[d\left(T x_{1}, T u_{2}\right)+d\left(T x_{2}, T u_{1}\right)\right]
\end{aligned}
$$

Using these notions, the authors proved the following interesting result (for the definition of $A_{0}$ and $B_{0}$, we refer the reader to the next section).

Theorem 1.4 [14] Let $(X, d)$ be a complete metric space and $A$ and $B$ be two nonempty, closed subsets of $X$ such that $B$ is approximatively compact with respect to $A$. Assume that $A_{0}$ and $B_{0}$ are nonempty, and $T: A \rightarrow B$ is a non-self-mapping such that:

(i) $T\left(A_{0}\right) \subseteq B_{0}$,

(ii) $T$ is a generalized proximal contraction mapping of the first kind. 
Then there exists $x \in A$ such that $B_{\mathrm{est}}(T)=\{x\}$. Further, for any fixed $x_{0} \in A_{0}$ the sequence $\left\{x_{n}\right\}$, defined by $d\left(x_{n+1}, T x_{n}\right)=d(A, B)$, converges to $x$.

They also proved that if instead, $A$ is approximatively compact with respect to $B$, and $T$ is a continuous generalized proximal contraction mapping of the second kind, then $T$ has a best proximity point ([14], Theorem 3.4). Furthermore if $T$ is a generalized proximal contraction mapping of the first kind, as well as of the second kind, then $T$ has a unique best proximity point in $A$ ([14], Theorem 3.6).

In this paper, inspired by the above notion, we introduce two new notions of cyclic generalized proximal contraction of the first kind, and of the second kind. We then establish some best proximity point theorems for these classes of mappings. We begin with the first contribution of this paper.

Definition 1.5 Let $(X, d)$ be a metric space and let $A, B$ be two nonempty subsets of $X$. A (cyclic) mapping $T: A \cup B \rightarrow A \cup B$ is said to be a cyclic generalized proximal contraction of the first kind, if there exist nonnegative real numbers $a, c, d$ with $\frac{a+c+d}{1-c-d}<\frac{1}{8}$ such that for all $x_{1}, x_{2}, u_{1}, u_{2}, \in A \cup B$, the conditions

$$
d\left(u_{1}, T x_{1}\right)=d\left(u_{2}, T x_{2}\right)=d(A, B)
$$

imply that

$$
\begin{aligned}
d\left(u_{1}, u_{2}\right) \leq & a d\left(x_{1}, x_{2}\right)+c\left[d\left(x_{1}, u_{1}\right)+d\left(x_{2}, u_{2}\right)\right] \\
& +d\left[d\left(x_{1}, u_{2}\right)+d\left(x_{2}, u_{1}\right)\right]+(1-c-d)\left(1-\frac{k}{2}\right) d(A, B),
\end{aligned}
$$

where $k=\sqrt{8 \frac{a+c+d}{1-c-d}}$.

Example 1.6 Let $X=\mathbb{R}$ and $d(x, y)=|x-y|$ be the Euclidean metric on $X$. Let $A=\left[0, \frac{\pi}{2}\right]$ and $B=\left[-\frac{\pi}{2}, 0\right]$ be subsets of $X$. Clearly, $d(A, B)=0$.

We define $T: A \cup B \rightarrow A \cup B$ by $T x=-\frac{1}{9} \sin x$. Therefore $T(A) \subseteq B$ and $T(B) \subseteq A$.

So if

$$
d\left(u_{1}, T x_{1}\right)=d\left(u_{2}, T x_{2}\right)=d(A, B)=0,
$$

then $u_{1}=T x_{1}=-\frac{1}{9} \sin x_{1}$ and $u_{2}=T x_{2}=-\frac{1}{9} \sin x_{2}$.

Therefor we have

$$
d\left(u_{1}, u_{2}\right)=\left|-\frac{1}{9} \sin x_{1}+\frac{1}{9} \sin x_{2}\right| \leq \frac{1}{9}\left|x_{1}-x_{2}\right| .
$$

So $T$ is a cyclic generalized proximal contraction of the first kind on $A \cup B$ with $a=\frac{1}{9}$, $c=d=0$, and $\frac{a+c+d}{1-c-d}=\frac{1}{9}<\frac{1}{8}$.

We now present the second new class of mappings.

Definition 1.7 Let $(X, d)$ be a metric space and let $A, B$ be two nonempty subsets of $X$. A (cyclic) mapping $T: A \cup B \rightarrow A \cup B$ is said to be a cyclic generalized proximal contraction 
of the second kind, if there exist nonnegative real numbers $a, c, d$ with $\frac{a+c+d}{1-c-d}<\frac{1}{8}$ such that for all $x_{1}, x_{2}, u_{1}, u_{2}, \in A \cup B$, the conditions

$$
d\left(u_{1}, T x_{1}\right)=d\left(u_{2}, T x_{2}\right)=d(A, B)
$$

imply that

$$
\begin{aligned}
d\left(T u_{1}, T u_{2}\right) \leq & a d\left(T x_{1}, T x_{2}\right)+c\left[d\left(T x_{1}, T u_{1}\right)+d\left(T x_{2}, T u_{2}\right)\right] \\
& +d\left[d\left(T x_{1}, T u_{2}\right)+d\left(T x_{2}, T u_{1}\right)\right]+(1-c-d)\left(1-\frac{k}{2}\right) d(A, B),
\end{aligned}
$$

where $k=\sqrt{8 \frac{a+c+d}{1-c-d}}$.

The next example shows that a cyclic generalized proximal contraction of the second kind is not necessarily a cyclic generalized proximal contraction of the first kind.

Example 1.8 Consider $X=\mathbb{R}^{2}$ endowed with the usual metric

$$
d\left(\left(x_{1}, x_{2}\right),\left(y_{1}, y_{2}\right)\right)=\sqrt{\left(x_{1}-y_{1}\right)^{2}+\left(x_{2}-y_{2}\right)^{2}}, \quad \text { for all }\left(x_{1}, x_{2}\right),\left(y_{1}, y_{2}\right) \in \mathbb{R}^{2} .
$$

Define $A:=\left\{(x, x): 0 \leq x \leq \frac{1}{2}\right\}$ and $B:=\{(0,0),(0,1)\}$. Then $d(A, B)=0$.

Now we define $T: A \cup B \rightarrow A \cup B$ by

$$
T(x, y)= \begin{cases}(0,0), & x=y \text { and } x \text { is rational } \\ (0,1), & x=y, \text { and } x \text { is not rational } \\ (0,0), & x=0, y=1\end{cases}
$$

Therefore $T(A) \subseteq B$ and $T(B) \subseteq A$. For every $\left(x_{1}, y_{1}\right),\left(x_{2}, y_{2}\right),\left(u_{1}, \dot{u}_{1}\right),\left(u_{2}, \dot{u}_{2}\right)$ in $A \cup B$, if $d\left(\left(u_{1}, \dot{u}_{1}\right), T\left(x_{1}, y_{1}\right)\right)=d(A, B)=0$ then $\left(u_{1}, \dot{u}_{1}\right)=T\left(x_{1}, y_{1}\right)=(0,0)$ or $(0,1)$. So

$$
T\left(u_{1}, \dot{u}_{1}\right)=(0,0) .
$$

Similarly, if $d\left(\left(u_{2}, \dot{u}_{2}\right), T\left(x_{2}, y_{2}\right)\right)=d(A, B)=0$ then $\left(u_{2}, \dot{u}_{2}\right)=T\left(x_{2}, y_{2}\right)=(0,0)$ or $(0,1)$. So

$$
T\left(u_{2}, \dot{u}_{2}\right)=(0,0)
$$

Therefore for all $a, c, d$ with $\frac{a+c+d}{1-c-d}<\frac{1}{8}$, we have

$$
\begin{aligned}
d\left(T\left(u_{1}, \dot{u}_{1}\right), T\left(u_{2}, \dot{u}_{2}\right)\right)=0 \leq & a d\left(T\left(x_{1}, y_{1}\right), T\left(x_{2}, y_{2}\right)\right) \\
& +c\left[d\left(T\left(x_{1}, y_{1}\right), T\left(u_{1}, \dot{u}_{1}\right)\right)+d\left(T\left(x_{2}, y_{2}\right), T\left(u_{2}, \dot{u}_{2}\right)\right)\right] \\
& +d\left[d\left(T\left(x_{1}, y_{1}\right), T\left(u_{2}, \dot{u}_{2}\right)\right)+d\left(T\left(x_{2}, y_{2}\right), T\left(u_{1}, \dot{u}_{1}\right)\right)\right] \\
& +(1-c-d)\left(1-\frac{k}{2}\right) d(A, B) .
\end{aligned}
$$

So $T$ is a cyclic generalized proximal contraction of the second kind. 
We now prove that $T$ is not a cyclic generalized proximal contraction of the first kind. It is clear that $\operatorname{diam}(A \cup B)=1$. If

$$
\left(x_{1}, y_{1}\right)=\left(\frac{1}{\sqrt{2}}, \frac{1}{\sqrt{2}}\right), \quad\left(u_{1}, \dot{u}_{1}\right)=(0,1), \quad\left(x_{2}, y_{2}\right)=\left(u_{2}, \dot{u}_{2}\right)=(0,0),
$$

then

$$
\begin{aligned}
& d\left(\left(u_{1}, \dot{u}_{1}\right), T\left(x_{1}, y_{1}\right)\right)=d\left(\left(u_{2}, \dot{u}_{2}\right), T\left(x_{2}, y_{2}\right)\right)=d(A, B)=0 \quad \text { and } \\
& d\left(\left(u_{1}, \dot{u}_{1}\right),\left(u_{2}, \dot{u}_{2}\right)\right)=1 .
\end{aligned}
$$

For all nonnegative real numbers $a, c, d$ with $\frac{a+c+d}{1-c-d}<\frac{1}{8}<1$, we have $a+2 c+2 d<1$. Therefore

$$
\begin{aligned}
& a d\left(\left(x_{1}, y_{1}\right),\left(x_{2}, y_{2}\right)\right)+c\left[d\left(\left(x_{1}, y_{1}\right),\left(u_{1}, \dot{u}_{1}\right)\right)+d\left(\left(x_{2}, y_{2}\right),\left(u_{2}, \dot{u}_{2}\right)\right)\right] \\
& \quad+d\left[d\left(\left(x_{1}, y_{1}\right),\left(u_{2}, \dot{u}_{2}\right)\right)+d\left(\left(x_{2}, y_{2}\right),\left(u_{1}, \dot{u}_{1}\right)\right)\right]+(1-c-d)\left(1-\frac{k}{2}\right) d(A, B) \\
& \leq(a+2 c+2 d) \operatorname{diam}(A \cup B)=(a+2 c+2 d)<1=d\left(\left(u_{1}, \dot{u}_{1}\right),\left(u_{2}, \dot{u}_{2}\right)\right) .
\end{aligned}
$$

So $T$ is not a cyclic generalized proximal contraction of the first kind.

The above example shows that cyclic generalized proximal contractions are not necessarily continuous. In this paper we use this new notion to prove some best proximity point theorems for continuous cyclic generalized proximal contractions. The details are given in the next sections.

\section{Preliminaries}

This section is devoted to some definitions and statements that will be used in the sequel. Let $(X, d)$ be a metric space, $A, B$ be two nonempty subsets of $X$, and $T$ be a cycling mapping. We denote by $A_{0}$ and $B_{0}$ the following sets:

$$
\begin{aligned}
& A_{0}=\{x \in A: d(x, y)=d(A, B) \text { for some } y \in B\}, \\
& B_{0}=\{y \in B: d(x, y)=d(A, B) \text { for some } x \in A\} .
\end{aligned}
$$

In [15], sufficient conditions are provided to guarantee the non-emptiness of $A_{0}$ and $B_{0}$.

Definition 2.1 [16] Let $(X, d)$ be a metric space and $A, B$ be two nonempty subsets of $X$. The set $B$ is said to be approximatively compact with respect to $A$, if every sequence $\left\{y_{n}\right\}$ in $B$, satisfying the condition $d\left(x, y_{n}\right) \rightarrow d(x, B)$ for some $x \in A$, has a convergent subsequence.

Definition 2.2 [17] Let $X$ be a metric space and $A, B$ be nonempty subsets of $X$. A sequence $\left\{x_{n}\right\}$ in $A \cup B$, with $x_{2 n} \in A$ and $x_{2 n+1} \in B$ for all $n \geq 0$, is said to be a cyclically Cauchy sequence if

$$
\forall \epsilon>0 \exists N \in \mathbb{N}: d\left(x_{n}, x_{m}\right)<d(A, B)+\epsilon, \quad \forall n, m \geq N, n \text { is even and } m \text { is odd. }
$$

If $d(A, B)=0$, then a sequence $\left\{x_{n}\right\}$ in $A \cup B$ is cyclically Cauchy if and only if $\left\{x_{n}\right\}$ is Cauchy. 
Definition 2.3 [17] A pair $(A, B)$ of subsets of a metric space is said to be cyclically complete if for every cyclically Cauchy sequence $\left\{x_{n}\right\}$ in $A \cup B$, either $\left\{x_{2 n}\right\}$ or $\left\{x_{2 n+1}\right\}$ converges.

Definition 2.4 [18] A pair $(A, B)$ of subsets of a metric space is said to be proximally complete if for every cyclically Cauchy sequence $\left\{x_{n}\right\}$ in $A \cup B$, the sequences $\left\{x_{2 n}\right\}$ and $\left\{x_{2 n+1}\right\}$ have convergent subsequences in $A$ and $B$.

Theorem 2.5 [18] Let $A$ and $B$ be subsets of a metric space $X$. If $(A, B)$ is proximally complete, then $A_{0}$ and $B_{0}$ are closed subsets of $X$.

Definition 2.6 Let $(X, d)$ be a metric space.

- A pair $(A, B)$ of nonempty subsets of $X$ is said to be proximinal if for each $(x, y) \in A \times B$ there exists $\left(x_{0}, y_{0}\right) \in A \times B$ such that $d\left(x, y_{0}\right)=d\left(x_{0}, y\right)=d(A, B)$.

- A pair $(A, B)$ of nonempty subsets of $X$ is said to be sharp proximinal if for each $(x, y) \in A \times B$ there exists a unique $\left(x_{0}, y_{0}\right) \in A \times B$ such that $d\left(x, y_{0}\right)=d\left(x_{0}, y\right)=d(A, B)$.

- A pair $(A, B)$ of nonempty subsets of $X$ is said to be semi-sharp proximinal if for each $(x, y) \in A \times B$ there exists at most one $\left(x_{0}, y_{0}\right) \in A \times B$ such that $d\left(x, y_{0}\right)=d\left(x_{0}, y\right)=d(A, B)$.

We recall that every closed convex pair $(A, B)$ in a strictly convex Banach space is semisharp proximinal ([19], Lemma 2.5).

\section{Main results}

We begin this section by proving a theorem on the existence of best proximity points for cyclic generalized proximal contractions in metric spaces.

Theorem 3.1 Let $(A, B)$ be a proximally complete pair in a metric space $X$ and $A_{0} \neq \emptyset$. Let $T: A \cup B \rightarrow A \cup B$ be a mapping satisfying the following conditions:

(i) $T\left(A_{0}\right) \subseteq B_{0}, T\left(B_{0}\right) \subseteq A_{0}$,

(ii) $T$ is a continuous cyclic generalized proximal contraction of the first kind.

Then there exists $(x, y) \in A \times B$ such that

$$
d(x, T x)=d(A, B), \quad d(y, T y)=d(A, B) \quad \text { and } \quad d(x, y)=d(A, B) .
$$

Proof By the assumption $A_{0} \neq \emptyset$, so there exists $x_{0} \in A_{0}$. Since $T\left(A_{0}\right) \subseteq B_{0}$, it follows that $T\left(x_{0}\right) \in B_{0}$. So there exists $x_{1} \in A_{0}$ such that $d\left(x_{1}, T x_{0}\right)=d(A, B)$.

Continuing this process, we obtain a sequence $\left\{x_{n}\right\}$ in $A$, such that $d\left(x_{n+1}, T x_{n}\right)=d(A, B)$.

On the other hand, since $x_{0} \in A_{0}$, there exists $y_{0} \in B_{0}$ such that $d\left(x_{0}, y_{0}\right)=d(A, B)$, and since $T\left(B_{0}\right) \subseteq A_{0}$, it follows that $T\left(y_{0}\right) \in B_{0}$. So there exists $y_{1} \in B_{0}$ such that $d\left(y_{1}, T y_{0}\right)=$ $d(A, B)$.

Continuing this process, we obtain a sequence $\left\{y_{n}\right\}$ in $B$ such that $d\left(y_{n+1}, T y_{n}\right)=d(A, B)$. Now we define

$$
z_{n}= \begin{cases}x_{r}, & n=2 r, \\ y_{r}, & n=2 r+1 .\end{cases}
$$


We will prove that $\left\{z_{n}\right\}$ is a cyclically Cauchy sequence in $A \cup B$. To do this, we need verify that $\lim _{m, n \rightarrow \infty} d\left(z_{2 n}, z_{2 m+1}\right)=d(A, B)$, or equivalently,

$$
\lim _{m, n \rightarrow \infty} d\left(x_{n}, y_{m}\right)=d(A, B)
$$

Let $m \leq n$. Since $d\left(x_{n+1}, T x_{n}\right)=d\left(y_{m+1}, T y_{m}\right)=d(A, B)$ and $T$ is a cyclic generalized proximal contraction of the first kind on $A \cup B$, we have

$$
\begin{aligned}
d\left(x_{n+1}, y_{m+1}\right) \leq & a d\left(x_{n}, y_{m}\right)+c\left[d\left(x_{n}, x_{n+1}\right)+d\left(y_{m}, y_{m+1}\right)\right] \\
& +d\left[d\left(x_{n}, y_{m+1}\right)+d\left(x_{n+1}, y_{m}\right)\right] \\
& +(1-c-d)\left(1-\frac{k}{2}\right) d(A, B) .
\end{aligned}
$$

By using the inequalities

$$
\begin{aligned}
& d\left(x_{n}, x_{n+1}\right) \leq d\left(x_{n}, y_{m}\right)+d\left(y_{m}, y_{m+1}\right)+d\left(y_{m+1}, x_{n+1}\right), \\
& d\left(x_{n}, y_{m+1}\right) \leq d\left(x_{n}, y_{m}\right)+d\left(y_{m}, y_{m+1}\right) \\
& d\left(x_{n+1}, y_{m}\right) \leq d\left(x_{n+1}, y_{m+1}\right)+d\left(y_{m}, y_{m+1}\right)
\end{aligned}
$$

we obtain

$$
\begin{aligned}
d\left(x_{n+1}, y_{m+1}\right) \leq & a d\left(x_{n}, y_{m}\right) \\
& +(c+d)\left[d\left(x_{n}, y_{m}\right)+d\left(x_{n+1}, y_{m+1}\right)+2 d\left(y_{m}, y_{m+1}\right)\right] \\
& +(1-c-d)\left(1-\frac{k}{2}\right) d(A, B),
\end{aligned}
$$

and hence

$$
\begin{aligned}
d\left(x_{n+1}, y_{m+1}\right) \leq & \frac{a+c+d}{1-c-d} d\left(x_{n}, y_{m}\right)+2 \frac{c+d}{1-c-d} d\left(y_{m}, y_{m+1}\right) \\
& +\left(1-\frac{k}{2}\right) d(A, B) .
\end{aligned}
$$

Since $2(c+d) \leq 2(a+c+d)$, it follows that

$$
2 \frac{c+d}{1-c-d} \leq 2 \frac{a+c+d}{1-c-d}=2 \frac{k^{2}}{8}=\frac{k^{2}}{4} \leq \frac{k}{4} .
$$

So we have

$$
d\left(x_{n+1}, y_{m+1}\right) \leq \frac{k^{2}}{8} d\left(x_{n}, y_{m}\right)+\frac{k}{4} d\left(y_{m}, y_{m+1}\right)+\left(1-\frac{k}{2}\right) d(A, B) .
$$

Note also that

$$
d\left(y_{m}, T y_{m-1}\right)=d\left(y_{m+1}, T y_{m}\right)=d(A, B)
$$


and that $T$ is a cyclic generalized proximal contraction of the first kind, so that a manipulation yields

$$
\begin{aligned}
d\left(y_{m}, y_{m+1}\right) \leq & a d\left(y_{m-1}, y_{m}\right) \\
& +(c+d)\left[d\left(y_{m}, y_{m+1}\right)+d\left(y_{m-1}, y_{m}\right)\right] \\
& +(1-c-d)\left(1-\frac{k}{2}\right) d(A, B) .
\end{aligned}
$$

Therefore

$$
d\left(y_{m}, y_{m+1}\right) \leq \frac{a+c+d}{1-c-d} d\left(y_{m-1}, y_{m}\right)+\left(1-\frac{k}{2}\right) d(A, B),
$$

from which it follows that

$$
d\left(y_{m}, y_{m+1}\right) \leq \frac{k^{2}}{8} d\left(y_{m-1}, y_{m}\right)+\left(1-\frac{k}{2}\right) d(A, B) .
$$

It now follows from equations (7), (9) that

$$
\begin{aligned}
d\left(x_{n+1}, y_{m+1}\right) \leq & \frac{k^{2}}{8}\left[\frac{k^{2}}{8} d\left(x_{n-1}, y_{m-1}\right)+\frac{k}{4} d\left(y_{m-1}, y_{m}\right)+\left(1-\frac{k}{2}\right) d(A, B)\right] \\
& +\frac{k}{4}\left[\frac{k^{2}}{8} d\left(y_{m-1}, y_{m}\right)+\left(1-\frac{k}{2}\right) d(A, B)\right]+\left(1-\frac{k}{2}\right) d(A, B) \\
\leq & \frac{k^{4}}{64} d\left(x_{n-1}, y_{m-1}\right)+\frac{k^{3}}{16} d\left(y_{m-1}, y_{m}\right)+\left(\frac{k^{2}}{8}+\frac{k}{4}+1\right)\left(1-\frac{k}{2}\right) d(A, B) \\
\leq & \left(\frac{k}{2}\right)^{4} d\left(x_{n-1}, y_{m-1}\right)+\left(\frac{k}{2}\right)^{3} d\left(y_{m-1}, y_{m}\right) \\
& +\left(\left(\frac{k}{2}\right)^{2}+\frac{k}{2}+1\right)\left(1-\frac{k}{2}\right) d(A, B) \\
\leq & \left(\frac{k}{2}\right)^{4}\left[\frac{k^{2}}{8} d\left(x_{n-2}, y_{m-2}\right)+\frac{k}{4} d\left(y_{m-2}, y_{m-1}\right)+\left(1-\frac{k}{2}\right) d(A, B)\right] \\
& +\left(\frac{k}{2}\right)^{3}\left[\frac{k^{2}}{8} d\left(y_{m-2}, y_{m-1}\right)+\left(1-\frac{k}{2}\right) d(A, B)\right] \\
& +\left(\left(\frac{k}{2}\right)^{2}+\frac{k}{2}+1\right)\left(1-\frac{k}{2}\right) d(A, B) \\
\leq & \left(\frac{k}{2}\right)^{6} d\left(x_{n-2}, y_{m-2}\right)+\left(\frac{k}{2}\right)^{5} d\left(y_{m-2}, y_{m-1}\right) \\
& +\left(\left(\frac{k}{2}\right)^{4}+\left(\frac{k}{2}\right)^{3}+\left(\frac{k}{2}\right)^{2}+\frac{k}{2}+1\right)\left(1-\frac{k}{2}\right) d(A, B) .
\end{aligned}
$$


Now, we assume that the above relation holds for $r<m$, and we will show that it holds for $r=m$. To this end, we note that

$$
\begin{aligned}
d\left(x_{n+1}, y_{m+1}\right) \leq & \left(\frac{k}{2}\right)^{2 r+2} d\left(x_{n-r}, y_{m-r}\right)+\left(\frac{k}{2}\right)^{2 r+1} d\left(y_{m-r}, y_{m-r+1}\right) \\
& +\left(\left(\frac{k}{2}\right)^{2 r}+\left(\frac{k}{2}\right)^{2 r-1}+\cdots+\left(\frac{k}{2}\right)^{2}+\frac{k}{2}+1\right)\left(1-\frac{k}{2}\right) d(A, B) \\
\leq & \left(\frac{k}{2}\right)^{2 r+2}\left[\frac{k^{2}}{8} d\left(x_{n-(r+1)}, y_{m-(r+1)}\right)+\frac{k}{4} d\left(y_{m-(r+1)}, y_{m-r}\right)\right. \\
& \left.+\left(1-\frac{k}{2}\right) d(A, B)\right] \\
& +\left(\frac{k}{2}\right)^{2 r+1}\left[\frac{k^{2}}{8} d\left(y_{m-(r+1)}, y_{m-r}\right)+\left(1-\frac{k}{2}\right) d(A, B)\right] \\
& +\left(\left(\frac{k}{2}\right)^{2 r}+\left(\frac{k}{2}\right)^{2 r-1}+\cdots+\left(\frac{k}{2}\right)^{2}+\frac{k}{2}+1\right)\left(1-\frac{k}{2}\right) d(A, B) \\
\leq & \left(\frac{k}{2}\right)^{2(r+1)+2} d\left(x_{n-(r-1)}, y_{m-(r-1)}\right)+\left(\frac{k}{2}\right)^{2(r+1)+1} d\left(y_{m-(r+1)}, y_{m-r}\right) \\
& +\left(\left(\frac{k}{2}\right)^{2 r+2}+\left(\frac{k}{2}\right)^{2 r+1}+\left(\frac{k}{2}\right)^{2 r}+\cdots\right. \\
& \left.+\left(\frac{k}{2}\right)^{2}+\frac{k}{2}+1\right)\left(1-\frac{k}{2}\right) d(A, B) .
\end{aligned}
$$

So for $r=m$, we have

$$
\begin{aligned}
d\left(x_{n+1}, y_{m+1}\right) & \\
\leq & \left(\frac{k}{2}\right)^{2 m+2} d\left(x_{n-m}, y_{0}\right)+\left(\frac{k}{2}\right)^{2 m+1} d\left(y_{0}, y_{1}\right) \\
& +\left(\left(\frac{k}{2}\right)^{2 m}+\left(\frac{k}{2}\right)^{2 m-1}+\cdots+\left(\frac{k}{2}\right)^{2}+\frac{k}{2}+1\right)\left(1-\frac{k}{2}\right) d(A, B) \\
= & \left(\frac{k}{2}\right)^{2 m+2} d\left(x_{n-m}, y_{0}\right)+\left(\frac{k}{2}\right)^{2 m+1} d\left(y_{0}, y_{1}\right)+\left(1-\left(\frac{k}{2}\right)^{2 m+1}\right) d(A, B) .
\end{aligned}
$$

We now prove that the sequence $\left\{x_{n}\right\}$ is bounded. Suppose to the contrary that it is not bounded, so for

$$
M=\frac{k^{2}+2 k}{8-k^{2}} d\left(y_{0}, y_{1}\right)+\frac{8-4 k}{8-k^{2}} d(A, B),
$$

there exists a natural number $n$ such that $d\left(x_{n}, y_{1}\right) \leq M$ and $d\left(x_{n+1}, y_{1}\right)>M$. Now, we have

$$
\begin{aligned}
M & <d\left(x_{n+1}, y_{1}\right) \leq \frac{k^{2}}{8} d\left(x_{n}, y_{0}\right)+\frac{k}{4} d\left(y_{0}, y_{1}\right)+\left(1-\frac{k}{2}\right) d(A, B) \\
& \leq \frac{k^{2}}{8}\left[d\left(x_{n}, y_{1}\right)+d\left(y_{0}, y_{1}\right)\right]+\frac{k}{4} d\left(y_{0}, y_{1}\right)+\left(1-\frac{k}{2}\right) d(A, B)
\end{aligned}
$$




$$
\begin{aligned}
& \leq \frac{k^{2}}{8} M+\left(\frac{k^{2}}{8}+\frac{k}{4}\right) d\left(y_{0}, y_{1}\right)+\left(1-\frac{k}{2}\right) d(A, B) \\
& =\frac{k^{2}}{8} M+\left(1-\frac{k^{2}}{8}\right) M=M,
\end{aligned}
$$

which is a contradiction. This argument shows that the sequence $\left\{x_{n}\right\}$ is bounded, so that

$$
\begin{aligned}
& \lim _{m, n \rightarrow \infty} d\left(x_{n+1}, y_{m+1}\right) \\
& \quad \leq \lim _{m, n \rightarrow \infty}\left[\left(\frac{k}{2}\right)^{2 m+2} d\left(x_{n-m}, y_{0}\right)+\left(\frac{k}{2}\right)^{2 m+1} d\left(y_{0}, y_{1}\right)+\left(1-\left(\frac{k}{2}\right)^{2 m+1}\right) d(A, B)\right] \\
& \quad=d(A, B) .
\end{aligned}
$$

Therefore $\left\{z_{n}\right\}$ is a cyclically Cauchy sequence in $A \cup B$. By our assumption, $(A, B)$ is a proximally complete pair in $X$ so that the sequences $\left\{x_{n}\right\}$ and $\left\{y_{m}\right\}$ have convergent subsequences in $A$ and $B$, respectively, that is, there exist subsequences $\left\{x_{n_{r}}\right\}$ and $\left\{y_{m_{s}}\right\}$ of $\left\{x_{n}\right\}$ and $\left\{y_{m}\right\}$ and $(x, y) \in(A \times B)$ such that

$$
\lim _{r \rightarrow \infty} x_{n_{r}}=x \text { and } \lim _{s \rightarrow \infty} y_{m_{s}}=y .
$$

Since $T$ is continuous, it follows that

$$
d(x, T x)=\lim _{r \rightarrow \infty} d\left(x_{n_{r+1}}, T x_{n_{r}}\right)=d(A, B)
$$

and

$$
d(y, T y)=\lim _{s \rightarrow \infty} d\left(y_{m_{s+1}}, T x_{m_{s}}\right)=d(A, B) .
$$

Finally, from (14) and (15) we obtain

$$
d(x, y)=\lim _{r, s \rightarrow \infty} d\left(x_{n_{r}}, y_{m_{s}}\right)=d(A, B) .
$$

Example 3.2 Let $X=\mathbb{R}$ and $d(x, y)=|x-y|$ be the Euclidean metric on $X$. Let $A=\left[0, \frac{\pi}{2}\right]$ and $B=\left[-\frac{\pi}{2}, 0\right]$ be subsets of $X$. Since $A$ and $B$ are closed subsets of the complete metric space $\mathbb{R}$ and $d(A, B)=0$, it follows that $(A, B)$ is a proximally complete pair. It is clear that $A_{0}=B_{0}=\{0\}$, moreover, $T\left(A_{0}\right) \subseteq B_{0}$ and $T\left(B_{0}\right) \subseteq A_{0}$. As in Example 1.6, we define $T$ : $A \cup B \rightarrow A \cup B$ by $T x=-\frac{1}{9} \sin x$. It is easy to see that $T$ is a continuous cyclic generalized proximal contraction of the first kind on $A \cup B$. Therefore all the conditions of Theorem 3.1 are fulfilled, so there exists $(x, y) \in A \times B$ such that

$$
d(x, T x)=d(A, B), \quad d(y, T y)=d(A, B) \quad \text { and } \quad d(x, y)=d(A, B) .
$$

Since $T 0=0$, it follows that $d(0, T 0)=0=d(A, B)$. Note also that $(0,0) \in A \times B$, and $d(0,0)=0=d(A, B)$.

Theorem 3.3 Let $(A, B)$ be a cyclically complete pair in a metric space $X$ and $A_{0} \neq \emptyset$. Let $A$ be approximatively compact with respect to $B$ and $B$ be approximatively compact with respect to $A$. Let $T: A \cup B \rightarrow A \cup B$ be a mapping satisfying the following conditions: 
(i) $T\left(A_{0}\right) \subseteq B_{0}, T\left(B_{0}\right) \subseteq A_{0}$,

(ii) $T$ is a continuous cyclic generalized proximal contraction of the first kind.

Then there exists $(x, y) \in A \times B$ such that

$$
d(x, T x)=d(A, B), \quad d(y, T y)=d(A, B) \quad \text { and } \quad d(x, y)=d(A, B) .
$$

Proof Following the same lines as in the proof of Theorem 3.1, we can construct the sequences $\left\{x_{n}\right\}$ in $A$ and $\left\{y_{n}\right\}$ in $B$ such that $d\left(x_{n+1}, T x_{n}\right)=d(A, B)$ and $d\left(y_{n+1}, T y_{n}\right)=d(A, B)$. Now, define the sequence $\left\{z_{n}\right\}$ by

$$
z_{n}= \begin{cases}x_{r}, & n=2 r, \\ y_{r}, & n=2 r+1 .\end{cases}
$$

It follows that $\left\{z_{n}\right\}$ is a cyclically Cauchy sequence in $A \cup B$. Moreover,

$$
\lim _{m, n \rightarrow \infty} d\left(x_{n}, y_{m}\right)=d(A, B)
$$

Since by our assumption, $(A, B)$ is a cyclically complete pair in $X$, either $\left\{x_{n}\right\}$ or $\left\{y_{m}\right\}$ converges. Assume the sequence $\left\{x_{n}\right\}$ converges in $A$, so there exists $x \in A$ such that

$$
\lim _{n \rightarrow \infty} x_{n}=x
$$

Note also that

$$
d(x, B) \leq d\left(y_{m}, x\right) \leq d\left(y_{m}, x_{n}\right)+d\left(x_{n}, x\right),
$$

from which it follows that

$$
d(x, B) \leq \lim _{m \rightarrow \infty} \lim _{n \rightarrow \infty} d\left(y_{m}, x\right) \leq d(A, B) \leq d(x, B),
$$

and finally

$$
d(x, B)=\lim _{m \rightarrow \infty} d\left(y_{m}, x\right) .
$$

Since $B$ is approximatively compact with respect to $A$, there exist a subsequence $\left\{y_{m_{s}}\right\}$ of $\left\{y_{m}\right\}$ and an element $y \in B$ such that

$$
\lim _{s \rightarrow \infty} y_{m_{s}}=y .
$$

Now, we use the continuity of $T$ to write

$$
d(x, T x)=\lim _{n \rightarrow \infty} d\left(x_{n+1}, T x_{n}\right)=d(A, B)
$$

and

$$
d(y, T y)=\lim _{s \rightarrow \infty} d\left(y_{m_{s+1}}, T y_{m_{s}}\right)=d(A, B) .
$$


Finally, it follows from (16), (17), and (19) that

$$
d(x, y)=\lim _{n, s \rightarrow \infty} d\left(x_{n}, y_{m_{s}}\right)=d(A, B)
$$

We now manage to prove the existence of best proximity points for cyclic generalized proximal contractions of the second kind.

Theorem 3.4 Let $(A, B)$ be a proximally complete pair in a metric space $X$ and $A_{0} \neq \emptyset$. Let $A$ be approximatively compact with respect to $B$ and $B$ be approximatively compact with respect to $A$. Let $T: A \cup B \rightarrow A \cup B$ be a mapping satisfying the following conditions:

(i) $T\left(A_{0}\right) \subseteq B_{0}, T\left(B_{0}\right) \subseteq A_{0}$,

(ii) $T$ is a continuous cyclic generalized proximal contraction of the second kind.

Then there exists $(x, y) \in A \times B$ such that

$$
d(x, T x)=d(A, B), \quad d(y, T y)=d(A, B) \quad \text { and } \quad d(T x, T y)=d(A, B) .
$$

Proof Following the same lines as in the proof of Theorem 3.1, it is possible to construct the sequences $\left\{x_{n}\right\}$ in $A$ and $\left\{y_{n}\right\}$ in $B$ such that

$$
d\left(x_{n+1}, T x_{n}\right)=d(A, B), \quad d\left(y_{n+1}, T y_{n}\right)=d(A, B) .
$$

Now, we define

$$
z_{n}= \begin{cases}T x_{r}, & n=2 r \\ T y_{r}, & n=2 r+1 .\end{cases}
$$

We prove that $\left\{z_{n}\right\}$ is a cyclically Cauchy sequence in $A \cup B$.

To this end, we must prove that $\lim _{m, n \rightarrow \infty} d\left(z_{2 n}, z_{2 m+1}\right)=d(A, B)$ or, equivalently,

$$
\lim _{m, n \rightarrow \infty} d\left(T x_{n}, T y_{m}\right)=d(A, B)
$$

Let $m \leq n$. Since $d\left(x_{n+1}, T x_{n}\right)=d\left(y_{m+1}, T y_{m}\right)=d(A, B)$ and $T$ is a cyclic generalized proximal contraction of the second kind on $A \cup B$, we have

$$
\begin{aligned}
d\left(T x_{n+1}, T y_{m+1}\right) \leq & a d\left(T x_{n}, T y_{m}\right)+c\left[d\left(T x_{n}, T x_{n+1}\right)+d\left(T y_{m}, T y_{m+1}\right)\right] \\
& +d\left[d\left(T x_{n}, T y_{m+1}\right)+d\left(T x_{n+1}, T y_{m}\right)\right] \\
& +(1-c-d)\left(1-\frac{k}{2}\right) d(A, B) .
\end{aligned}
$$

Using the triangle inequalities, as in the proof of Theorem 3.1, we have

$$
\begin{aligned}
d\left(T x_{n+1}, T y_{m+1}\right) \leq & a d\left(T x_{n}, T y_{m}\right) \\
& +(c+d)\left[d\left(T x_{n}, T y_{m}\right)+d\left(T x_{n+1}, T y_{m+1}\right)+2 d\left(T y_{m}, T y_{m+1}\right)\right] \\
& +(1-c-d)\left(1-\frac{k}{2}\right) d(A, B)
\end{aligned}
$$


and hence

$$
\begin{aligned}
d\left(T x_{n+1}, T y_{m+1}\right) \leq & \frac{a+c+d}{1-c-d} d\left(T x_{n}, T y_{m}\right)+2 \frac{c+d}{1-c-d} d\left(T y_{m}, T y_{m+1}\right) \\
& +\left(1-\frac{k}{2}\right) d(A, B) .
\end{aligned}
$$

Since $2(c+d) \leq 2(a+c+d)$, it follows that

$$
2 \frac{c+d}{1-c-d} \leq 2 \frac{a+c+d}{1-c-d}=2 \frac{k^{2}}{8}=\frac{k^{2}}{4} \leq \frac{k}{4}
$$

and hence

$$
d\left(T x_{n+1}, T y_{m+1}\right) \leq \frac{k^{2}}{8} d\left(T x_{n}, T y_{m}\right)+\frac{k}{4} d\left(T y_{m}, T y_{m+1}\right)+\left(1-\frac{k}{2}\right) d(A, B) .
$$

Again, since $d\left(y_{m}, T y_{m-1}\right)=d\left(y_{m+1}, T y_{m}\right)=d(A, B)$ and $T$ is a cyclic generalized proximal contraction of the second kind on $A \cup B$, after some manipulations we have

$$
\begin{aligned}
d\left(T y_{m}, T y_{m+1}\right) \leq & a d\left(T y_{m-1}, T y_{m}\right)+(c+d)\left[d\left(T y_{m}, T y_{m+1}\right)+d\left(T y_{m-1}, T y_{m}\right)\right] \\
& +(1-c-d)\left(1-\frac{k}{2}\right) d(A, B) .
\end{aligned}
$$

Therefore

$$
d\left(T y_{m}, T y_{m+1}\right) \leq \frac{a+c+d}{1-c-d} d\left(T y_{m-1}, T y_{m}\right)+\left(1-\frac{k}{2}\right) d(A, B),
$$

from which it follows that

$$
d\left(T y_{m}, T y_{m+1}\right) \leq \frac{k^{2}}{8} d\left(T y_{m-1}, T y_{m}\right)+\left(1-\frac{k}{2}\right) d(A, B) .
$$

It now follows from equations (23) and (25) that

$$
\begin{aligned}
d\left(T x_{n+1}, T y_{m+1}\right) \leq & \frac{k^{2}}{8}\left[\frac{k^{2}}{8} d\left(T x_{n-1}, T y_{m-1}\right)+\frac{k}{4} d\left(T y_{m-1}, T y_{m}\right)+\left(1-\frac{k}{2}\right) d(A, B)\right] \\
& +\frac{k}{4}\left[\frac{k^{2}}{8} d\left(T y_{m-1}, T y_{m}\right)+\left(1-\frac{k}{2}\right) d(A, B)\right]+\left(1-\frac{k}{2}\right) d(A, B) \\
\leq & \frac{k^{4}}{64} d\left(T x_{n-1}, T y_{m-1}\right)+\frac{k^{3}}{16} d\left(T y_{m-1}, T y_{m}\right) \\
& +\left(\frac{k^{2}}{8}+\frac{k}{4}+1\right)\left(1-\frac{k}{2}\right) d(A, B) \\
\leq & \left(\frac{k}{2}\right)^{4} d\left(T x_{n-1}, T y_{m-1}\right)+\left(\frac{k}{2}\right)^{3} d\left(T y_{m-1}, T y_{m}\right) \\
& +\left(\left(\frac{k}{2}\right)^{2}+\frac{k}{2}+1\right)\left(1-\frac{k}{2}\right) d(A, B) \\
\leq & \left(\frac{k}{2}\right)^{4}\left[\frac{k^{2}}{8} d\left(T x_{n-2}, T y_{m-2}\right)+\frac{k}{4} d\left(T y_{m-2}, T y_{m-1}\right)+\left(1-\frac{k}{2}\right) d(A, B)\right]
\end{aligned}
$$




$$
\begin{aligned}
& \quad+\left(\frac{k}{2}\right)^{3}\left[\frac{k^{2}}{8} d\left(T y_{m-2}, T y_{m-1}\right)+\left(1-\frac{k}{2}\right) d(A, B)\right] \\
& +\left(\left(\frac{k}{2}\right)^{2}+\frac{k}{2}+1\right)\left(1-\frac{k}{2}\right) d(A, B) \\
& \leq\left(\frac{k}{2}\right)^{6} d\left(T x_{n-2}, T y_{m-2}\right)+\left(\frac{k}{2}\right)^{5} d\left(T y_{m-2}, T y_{m-1}\right) \\
& +\left(\left(\frac{k}{2}\right)^{4}+\left(\frac{k}{2}\right)^{3}+\left(\frac{k}{2}\right)^{2}+\frac{k}{2}+1\right)\left(1-\frac{k}{2}\right) d(A, B) .
\end{aligned}
$$

Now, we assume that the above relation is valid for $r<m$, and we try to conclude that it holds for $r=m$. To this end, we note that

$$
\begin{aligned}
d\left(T x_{n+1}, T y_{m+1}\right) \leq & \left(\frac{k}{2}\right)^{2 r+2} d\left(T x_{n-r}, T y_{m-r}\right)+\left(\frac{k}{2}\right)^{2 r+1} d\left(T y_{m-r}, T y_{m-r+1}\right) \\
& +\left(\left(\frac{k}{2}\right)^{2 r}+\left(\frac{k}{2}\right)^{2 r-1}+\cdots+\left(\frac{k}{2}\right)^{2}+\frac{k}{2}+1\right)\left(1-\frac{k}{2}\right) d(A, B) \\
\leq & \left(\frac{k}{2}\right)^{2 r+2}\left[\frac{k^{2}}{8} d\left(T x_{n-(r+1)}, T y_{m-(r+1)}\right)\right. \\
& \left.+\frac{k}{4} d\left(T y_{m-(r+1)}, T y_{m-r}\right)+\left(1-\frac{k}{2}\right) d(A, B)\right] \\
& +\left(\frac{k}{2}\right)^{2 r+1}\left[\frac{k^{2}}{8} d\left(T y_{m-(r+1)}, T y_{m-r}\right)+\left(1-\frac{k}{2}\right) d(A, B)\right] \\
& +\left(\left(\frac{k}{2}\right)^{2 r}+\left(\frac{k}{2}\right)^{2 r-1}+\cdots+\left(\frac{k}{2}\right)^{2}+\frac{k}{2}+1\right)\left(1-\frac{k}{2}\right) d(A, B) \\
\leq & \left(\frac{k}{2}\right)^{2(r+1)+2} d\left(T x_{n-(r-1)}, T y_{m-(r-1)}\right) \\
& +\left(\frac{k}{2}\right)^{2(r+1)+1} d\left(T y_{m-(r+1)}, T y_{m-r}\right) \\
& +\left(\left(\frac{k}{2}\right)^{2 r+2}+\left(\frac{k}{2}\right)^{2 r+1}+\left(\frac{k}{2}\right)^{2 r}+\cdots\right. \\
& \left.+\left(\frac{k}{2}\right)^{2}+\frac{k}{2}+1\right)\left(1-\frac{k}{2}\right) d(A, B) .
\end{aligned}
$$

So, for $r=m$, we have

$$
\begin{aligned}
d\left(T x_{n+1}, T y_{m+1}\right) \leq & \left(\frac{k}{2}\right)^{2 m+2} d\left(T x_{n-m}, T y_{0}\right)+\left(\frac{k}{2}\right)^{2 m+1} d\left(y_{0}, y_{1}\right) \\
& +\left(\left(\frac{k}{2}\right)^{2 m}+\left(\frac{k}{2}\right)^{2 m-1}+\cdots+\left(\frac{k}{2}\right)^{2}+\frac{k}{2}+1\right)\left(1-\frac{k}{2}\right) d(A, B) \\
= & \left(\frac{k}{2}\right)^{2 m+2} d\left(T x_{n-m}, T y_{0}\right) \\
& +\left(\frac{k}{2}\right)^{2 m+1} d\left(T y_{0}, T y_{1}\right)+\left(1-\left(\frac{k}{2}\right)^{2 m+1}\right) d(A, B) .
\end{aligned}
$$


Now we prove that the sequence $\left\{T x_{n}\right\}$ is bounded. Suppose not, so, for

$$
M=\frac{k^{2}+2 k}{8-k^{2}} d\left(T y_{0}, T y_{1}\right)+\frac{8-4 k}{8-k^{2}} d(A, B),
$$

there exists a natural number $n$ such that $d\left(T x_{n}, T y_{1}\right) \leq M$ and $d\left(T x_{n+1}, T y_{1}\right)>M$. Now we have

$$
\begin{aligned}
M & <d\left(T x_{n+1}, T y_{1}\right) \leq \frac{k^{2}}{8} d\left(T x_{n}, T y_{0}\right)+\frac{k}{4} d\left(T y_{0}, T y_{1}\right)+\left(1-\frac{k}{2}\right) d(A, B) \\
& \leq \frac{k^{2}}{8}\left[d\left(T x_{n}, T y_{1}\right)+d\left(T y_{0}, T y_{1}\right)\right]+\frac{k}{4} d\left(T y_{0}, T y_{1}\right)+\left(1-\frac{k}{2}\right) d(A, B) \\
& \leq \frac{k^{2}}{8} M+\left(\frac{k^{2}}{8}+\frac{k}{4}\right) d\left(T y_{0}, T y_{1}\right)+\left(1-\frac{k}{2}\right) d(A, B) \\
& =\frac{k^{2}}{8} M+\left(1-\frac{k^{2}}{8}\right) M=M,
\end{aligned}
$$

which is a contradiction. Therefore the sequence $\left\{T x_{n}\right\}$ is bounded. So we have

$$
\begin{aligned}
& \lim _{m, n \rightarrow \infty} d\left(T x_{n+1}, T y_{m+1}\right) \\
& \quad \leq \lim _{m, n \rightarrow \infty}\left[\left(\frac{k}{2}\right)^{2 m+2} d\left(T x_{n-m}, y_{0}\right)+\left(\frac{k}{2}\right)^{2 m+1} d\left(T y_{0}, T y_{1}\right)+\left(1-\left(\frac{k}{2}\right)^{2 m+1}\right) d(A, B)\right] \\
& \quad=d(A, B) .
\end{aligned}
$$

This implies that the sequence $\left\{z_{n}\right\}$ is cyclically Cauchy in $A \cup B$. But by assumption, $(A, B)$ is a proximally complete pair in $X$, so that both sequences $\left\{T x_{n}\right\}$ and $\left\{T y_{m}\right\}$ have convergent subsequences in $B$ and $A$, respectively. This means that there exist subsequences $\left\{T x_{n_{r}}\right\}$ and $\left\{T y_{m_{s}}\right\}$ of $\left\{T x_{n}\right\}$ and $\left\{T y_{m}\right\}$ and $\left(y_{0}, x_{0}\right) \in(B \times A)$ such that

$$
\lim _{r \rightarrow \infty} T x_{n_{r}}=y_{0} \quad \text { and } \quad \lim _{s \rightarrow \infty} T y_{m_{s}}=x_{0} .
$$

Moreover, we have

$$
\begin{aligned}
d\left(y_{0}, A\right) & \leq d\left(y_{0}, x_{n_{r+1}}\right) \leq d\left(y_{0}, T x_{n_{r}}\right)+d\left(T x_{n_{r}}, x_{n_{r+1}}\right) \\
& \leq d\left(y_{0}, T x_{n_{r}}\right)+d(A, B) \leq d\left(y_{0}, T x_{n_{r}}\right)+d\left(y_{0}, A\right) .
\end{aligned}
$$

Taking the limit as $r \rightarrow \infty$, we conclude that $d\left(y_{0}, x_{n_{r+1}}\right) \rightarrow d\left(y_{0}, A\right)$. Since $A$ is approximatively compact with respect to $B$, the sequence $\left\{x_{n_{r}}\right\}$ has a subsequence $\left\{x_{n_{r_{t}}}\right\}$ converging to some $x \in A$. Now, using the continuity of $T$, we obtain

$$
d(x, T x)=\lim _{t \rightarrow \infty} d\left(x_{n_{r_{t+1}}}, T x_{n_{r_{t}}}\right)=d(A, B)
$$

that is, $x \in B_{\text {est }}(T)$. Similarly

$$
\begin{aligned}
d\left(x_{0}, B\right) & \leq d\left(x_{0}, y_{m_{s+1}}\right) \leq d\left(x_{0}, T y_{m_{s}}\right)+d\left(T y_{m_{s}}, y_{m_{s+1}}\right) \\
& \leq d\left(x_{0}, T y_{m_{s}}\right)+d(A, B) \leq d\left(x_{0}, T y_{m_{s}}\right)+d\left(x_{0}, B\right) .
\end{aligned}
$$


Taking the limit as $s \rightarrow \infty$, we get $d\left(x_{0}, y_{m_{s+1}}\right) \rightarrow d\left(x_{0}, B\right)$. Since $B$ is approximatively compact with respect to $A$, the sequence $\left\{y_{m_{s}}\right\}$ has a subsequence $\left\{y_{m_{i}}\right\}$ converging to some $y \in B$. Now, using the continuity of $T$, we obtain

$$
d(y, T y)=\lim _{i \rightarrow \infty} d\left(y_{m_{s_{i+1}}}, T y_{m_{s_{i}}}\right)=d(A, B)
$$

that is, $y \in B_{\text {est }}(T)$. Finally, from (30) we have

$$
d(T x, T y)=\lim _{t, i \rightarrow \infty} d\left(T x_{n_{r_{t}}}, T y_{m_{s_{i}}}\right)=d(A, B) .
$$

Example 3.5 Let $X=\mathbb{R}^{2}$ be endowed with the usual metric

$$
d\left(\left(x_{1}, x_{2}\right),\left(y_{1}, y_{2}\right)\right)=\sqrt{\left(x_{1}-y_{1}\right)^{2}+\left(x_{2}-y_{2}\right)^{2}} .
$$

We define $A:=\{(x, x): 0 \leq x \leq 1\}$ and $B:=\{(x,-x): 0 \leq x \leq 1\}$. Clearly $d(A, B)=0$ and $A_{0}=B_{0}=\{(0,0)\}$. So $A_{0} \neq \emptyset$. Since $A$ and $B$ are closed subsets of the complete metric space $\mathbb{R}^{2}$, and $d(A, B)=0$, it follows that $(A, B)$ is a proximally complete pair. Also, because of the compactness of $A$ and $B$, we conclude that $A$ is approximatively compact with respect to $B$ and $B$ is approximatively compact with respect to $A$. Now we define $T: A \cup B \rightarrow A \cup B$ by

$$
T(x, y)= \begin{cases}\frac{1}{3}(x,-x), & y=x \\ \frac{1}{3}(x, x), & y=-x .\end{cases}
$$

Therefore $T(A) \subseteq B$ and $T(B) \subseteq A$. Also $T\left(A_{0}\right) \subseteq B_{0}$ and $T\left(B_{0}\right) \subseteq A_{0}$. For every $\left(x_{1}, y_{1}\right)$, $\left(x_{2}, y_{2}\right),\left(u_{1}, \dot{u}_{1}\right),\left(u_{2}, \dot{u}_{2}\right)$ in $A \cup B$, if $d\left(\left(u_{1}, \dot{u}_{1}\right), T\left(x_{1}, y_{1}\right)\right)=d(A, B)=0$ then

$$
\left(u_{1}, \dot{u}_{1}\right)=T\left(x_{1}, y_{1}\right)= \begin{cases}\frac{1}{3}\left(x_{1},-x_{1}\right), & \text { if } y_{1}=x_{1}, \\ \frac{1}{3}\left(x_{1}, x_{1}\right), & \text { if } y_{1}=-x_{1} .\end{cases}
$$

So

$$
\begin{aligned}
T\left(u_{1}, \dot{u}_{1}\right) & = \begin{cases}T\left(\frac{1}{3} x_{1},-\frac{1}{3} x_{1}\right), & \text { if } y_{1}=x_{1}, \\
T\left(\frac{1}{3} x_{1}, \frac{1}{3} x_{1}\right), & \text { if } y_{1}=-x_{1},\end{cases} \\
& = \begin{cases}\frac{1}{9}\left(x_{1}, x_{1}\right), & \text { if } y_{1}=x_{1}, \\
\frac{1}{9}\left(x_{1},-x_{1}\right), & \text { if } y_{1}=-x_{1},\end{cases} \\
& =\frac{1}{9}\left(x_{1}, y_{1}\right) .
\end{aligned}
$$

Similarly, if $d\left(\left(u_{2}, \dot{u}_{2}\right), T\left(x_{2}, y_{2}\right)\right)=d(A, B)=0$, then

$$
\left(u_{2}, \dot{u}_{2}\right)=T\left(x_{2}, y_{2}\right)= \begin{cases}\frac{1}{3}\left(x_{2},-x_{2}\right), & \text { if } y_{2}=x_{2}, \\ \frac{1}{3}\left(x_{2}, x_{2}\right), & \text { if } y_{2}=-x_{2} .\end{cases}
$$


So

$$
\begin{aligned}
T\left(u_{1}, \dot{u}_{1}\right) & = \begin{cases}T\left(\frac{1}{3} x_{2},-\frac{1}{3} x_{2}\right), & \text { if } y_{2}=x_{2}, \\
T\left(\frac{1}{3} x_{2}, \frac{1}{3} x_{2}\right), & \text { if } y_{2}=-x_{2}\end{cases} \\
& = \begin{cases}\frac{1}{9}\left(x_{2}, x_{2}\right), & \text { if } y_{2}=x_{2}, \\
\frac{1}{9}\left(x_{2},-x_{2}\right), & \text { if } y_{2}=-x_{2},\end{cases} \\
& =\frac{1}{9}\left(x_{2}, y_{2}\right) .
\end{aligned}
$$

After routine calculations, one can show that $d\left(T\left(x_{1}, y_{1}\right), T\left(x_{2}, y_{2}\right)\right)=d\left(\left(x_{1}, y_{1}\right),\left(x_{2}, y_{2}\right)\right)$. Therefore we have

$$
d\left(T\left(u_{1}, \dot{u}_{1}\right), T\left(u_{2}, \dot{u}_{2}\right)\right)=\frac{1}{9} d\left(\left(x_{1}, y_{1}\right),\left(x_{2}, y_{2}\right)\right)=\frac{1}{9} d\left(T\left(x_{1}, y_{1}\right), T\left(x_{2}, y_{2}\right)\right) .
$$

So $T$ is a continuous cyclic generalized proximal contraction of the second kind on $A \cup B$ with $a=\frac{1}{9}, c=d=0$, and $\frac{a+c+d}{1-c-d}=\frac{1}{9}<\frac{1}{8}$.

Now, all the conditions of Theorem 3.4 are satisfied, so there exists $(x, y) \in A \times B$ such that

$$
d(x, T x)=d(A, B), \quad d(y, T y)=d(A, B) \quad \text { and } \quad d(T x, T y)=d(A, B) .
$$

Since $T(0,0)=\frac{1}{3}(0,0)=(0,0)$, we have $d((0,0), T(0,0))=0=d(A, B)$. Note also that $((0,0),(0,0)) \in A \times B$, and $d(T(0,0), T(0,0))=0=d(A, B)$.

Theorem 3.6 If in Theorem 3.4, instead of the assumption that $(A, B)$ is proximally complete, we assume that $(A, B)$ is cyclically complete, then the conclusion of Theorem 3.4 holds.

Proof Following the same lines of the proof of Theorem 3.4, we construct the sequences $\left\{x_{n}\right\}$ in $A$ and $\left\{y_{n}\right\}$ in $B$ such that $d\left(x_{n+1}, T x_{n}\right)=d(A, B)$ and $d\left(y_{n+1}, T y_{n}\right)=d(A, B)$. Now, define the sequence $\left\{z_{n}\right\}$ by

$$
z_{n}= \begin{cases}T x_{r}, & n=2 r, \\ T y_{r}, & n=2 r+1 .\end{cases}
$$

It is easy to see that $\left\{z_{n}\right\}$ is a cyclically Cauchy sequence in $A \cup B$, and

$$
\lim _{m, n \rightarrow \infty} d\left(T x_{n}, T y_{m}\right)=d(A, B)
$$

But, by assumption, $(A, B)$ is a cyclically complete pair in $X$ so that either $\left\{T x_{n}\right\}$ or $\left\{T y_{m}\right\}$ converges. Assume that the sequence $\left\{T x_{n}\right\}$ converges in $A$; and there exists $y_{0} \in B$ such that

$$
\lim _{n \rightarrow \infty} T x_{n}=y_{0}
$$

Note that

$$
d\left(A, y_{0}\right) \leq d\left(T y_{m}, y_{0}\right) \leq d\left(T y_{m}, T x_{n}\right)+d\left(T x_{n}, y_{0}\right)
$$


from which it follows that

$$
d\left(A, y_{0}\right) \leq \lim _{m \rightarrow \infty} \lim _{n \rightarrow \infty} d\left(T y_{m}, y_{0}\right) \leq d(A, B) \leq d\left(A, y_{0}\right)
$$

Since $A$ is approximatively compact with respect to $B$, there exist a subsequence $\left\{T y_{m_{s}}\right\}$ of $\left\{T y_{m}\right\}$ and an element $x_{0} \in A$ such that

$$
\lim _{s \rightarrow \infty} T y_{m_{s}}=x_{0}
$$

Moreover, we have

$$
\begin{aligned}
d\left(y_{0}, A\right) & \leq d\left(y_{0}, x_{n+1}\right) \leq d\left(y_{0}, T x_{n}\right)+d\left(T x_{n}, x_{n+1}\right) \\
& \leq d\left(y_{0}, T x_{n}\right)+d(A, B) \leq d\left(y_{0}, T x_{n}\right)+d\left(y_{0}, A\right) .
\end{aligned}
$$

Taking the limit as $n \rightarrow \infty$, we get $d\left(y_{0}, x_{n+1}\right) \rightarrow d\left(y_{0}, A\right)$. Since $A$ is approximatively compact with respect to $B$, the sequence $\left\{x_{n}\right\}$ has a subsequence $\left\{x_{n_{r}}\right\}$ converging to some $x \in A$. Now, using the continuity of $T$, we obtain

$$
d(x, T x)=\lim _{r \rightarrow \infty} d\left(x_{n_{r+1}}, T x_{n_{r}}\right)=d(A, B)
$$

that is, $x \in B_{\text {est }}(T)$. Similarly

$$
\begin{aligned}
d\left(x_{0}, B\right) & \leq d\left(x_{0}, y_{m_{s+1}}\right) \leq d\left(x_{0}, T y_{m_{s}}\right)+d\left(T y_{m_{s}}, y_{m_{s+1}}\right) \\
& \leq d\left(x_{0}, T y_{m_{s}}\right)+d(A, B) \leq d\left(x_{0}, T y_{m_{s}}\right)+d\left(x_{0}, B\right) .
\end{aligned}
$$

Taking the limit as $s \rightarrow \infty$, we get $d\left(x_{0}, y_{m_{s+1}}\right) \rightarrow d\left(x_{0}, B\right)$. Since $B$ is approximatively compact with respect to $A$, the sequence $\left\{y_{m_{s}}\right\}$ has a subsequence $\left\{y_{m_{s_{i}}}\right\}$ converging to some $y \in B$. Now, using the continuity of $T$, we obtain

$$
d(y, T y)=\lim _{i \rightarrow \infty} d\left(y_{m_{s_{i+1}}}, T y_{m_{s_{i}}}\right)=d(A, B)
$$

that is, $y \in B_{\text {est }}(T)$. Finally, from (34) we have

$$
d(T x, T y)=\lim _{n, s \rightarrow \infty} d\left(T x_{n}, T y_{m_{s}}\right)=d(A, B)
$$

\section{Conclusion}

In this paper we have introduced two new classes of mappings, namely, the cyclic generalized proximal contractions of the first kind, and of the second kind. As we have seen by the examples, these mappings are not necessarily continuous, so that it remains an open question to investigate whether the main results of this paper, Theorems 3.1 and 3.4, stand true if we remove the continuity assumption on $T$. The next open question is whether one can weaken the approximately compactness condition of the sets in the statement of Theorem 3.4 by a weaker condition, such as the closeness of $A_{0}$ and $B_{0}$. More precisely, we raise the following questions. 
Question 4.1 Is it possible to prove Theorem 3.1, and Theorem 3.4 without the continuity assumption on $T$ ?

Question 4.2 To what extent can the compactness conditions in Theorem 3.4 be relaxed? Does the result follow if we just assume that the pair $(A, B)$ is semi-sharp proximinal?

Competing interests

The authors declare that they have no competing interests.

\section{Authors' contributions}

All authors contributed equally and significantly in writing this paper. All authors read and approved the final manuscript.

\section{Author details}

${ }^{1}$ Department of Mathematics, Imam Khomeini International University, P.O. Box 288, Qazvin, 34149, Iran. ${ }^{2}$ Department of Mathematics, King Abdulaziz University, P.O. Box 80203, Jeddah, 21589, Saudi Arabia.

Received: 27 January 2016 Accepted: 24 May 2016 Published online: 04 June 2016

\section{References}

1. Abkar, A, Gabeleh, M: Best proximity points for cyclic mappings in ordered metric spaces. J. Optim. Theory Appl. 150(1), 188-193 (2011)

2. Abkar, A, Gabeleh, M: Generalized cyclic contractions in partially ordered metric spaces. Optim. Lett. 8(6), 1819-1830 (2012)

3. Caristi, J: Fixed point theorems for mappings satisfying inwardness conditions. Trans. Am. Math. Soc. 215, 241-251 (1976)

4. Edelstein, M: On fixed and periodic points under contractive mappings. J. Lond. Math. Soc. 37, 74-79 (1962)

5. Gabeleh, M: Best proximity point theorems via proximal non-self mappings. J. Optim. Theory Appl. 164(2), 565-576 (2015)

6. Gabeleh, M: Best proximity point theorems for single- and set-valued non-self mappings. Acta Math. Sci. 34(5), 1661-1669 (2014)

7. Gabeleh, M: Best proximity points and fixed point results for certain maps in Banach spaces. Numer. Funct. Anal. Optim. 36, 1013-1028 (2015)

8. Gabeleh, M, Shahzad, N: Existence and uniqueness of a solution for some nonlinear programming problems. Mediterr. J. Math. 12, 133-146 (2015)

9. Zabreko, PP, Krasnoselskii, MA: Iterations of operators and fixed points. Dokl. Akad. Nauk SSSR 196, 1006-1009 (1971)

10. Fan, K: Extensions of two fixed point theorems of F. E. Browder. Math. Z. 112, 234-240 (1969)

11. Prolla, JP: Fixed point theorems for set valued mappings and existence of best approximations. Numer. Funct. Anal. Optim. 5, 449-455 (1983)

12. Sehgal, VM, Singh, SP: A generalization to multifunctions of Fan's best approximation theorem. Proc. Am. Math. Soc. 102, 534-537 (1988)

13. Sehgal, VM, Singh, SP: A theorem on best approximations. Numer. Funct. Anal. Optim. 10, 181-184 (1989)

14. Sadiq Basha, S, Shahzad, N: Best proximity point theorems for generalized proximal contractions. Fixed Point Theory Appl. 2012, 42 (2012).

15. Kirk, WA, Reich, S, Veeramani, P: Proximinal retracts and best proximity pair theorems. Numer. Funct. Anal. Optim. 24 851-862 (2003)

16. Sadiq Basha, S: Best proximity points: optimal solutions. J. Optim. Theory Appl. 151, 210-216 (2011)

17. Karpagam, S, Agrawal, S: Best proximity points for cyclic contractions. Preprint

18. Espinola, R, Sankara Raju Kosuru, G, Veeramani, P: Pythagorean property and best proximity pair theorems. J. Optim. Theory Appl. 164, 534-550 (2015)

19. Sankara Raju Kosuru, G, Veeramani, P: On existence of best proximity pair theorems for relatively nonexpansive mappings. J. Nonlinear Convex Anal. 11(1), 71-77 (2010) 